\title{
Факторы профессиональной адаптации молодых преподавателей вуза
}

\author{
Е. П. БОНДАРЕВА \\ (КЕМЕРОВСКИЙ ИНСТИТУТ (ФИЛИАЛ) РОССИЙСКОГО ЭКОНОМИЧЕСКОГО УНИВЕРСИТЕТА \\ ИМ. Г. В. ПЛЕХАНОВА; УНИВЕРСИТЕТ ИМ. ИБРАГИМА ЧЕЧЕНА В Г. АГРЫ, ТУРЦИЯ), \\ C. A. CEPTEEB \\ (УНИВЕРСИТЕТ ИМ. ИБРАГИМА ЧЕЧЕНА В Г. АГРЫ, ТУРЦИЯ)
}

Актуальность исследования обусловлена противоречиями, характерными для сферы высшего образования в целом и Кемеровского государственного университета (г. Кемерово, Россия) в частности, а именно несоответствием между предьявляемыми требованиями к профессиональной деятельности преподавателя высшей школы, и их реализацией в собственной профессиональной деятельности в конкретных условиях труда; старением преподавательских кадров и отсутствием в вузах системы адаптации молодых преподавателей.

В статье представлены результаты эмпирического исследования профессиональной адаптации молодых преподавателей Кемеровского государственного университета в возрасте от 22 до 30 лет, проведенного в 2015 г. Анализ кадровой ситуации КемГУ показал, что в организации наблюдается тенденция сокращения профессорско-преподавательского состава, при этом доля молодых преподавателей на сегодняшний день составляет всего лишь 6,4\% от общего числа штатных преподавателей. Система адаптации молодых преподавателей и специальная служба, отвечающая за данное направление, в вузе отсутствуют, поэтому адаптивный процесс носит стихийный характер.

Анкетирование позволило выявить проблемные зоны в деятельности молодых преподавателей КемГУ, а также определить факторы, способствующие созданию благоприятных условий для вхождения в профессиональное русло.

Основной мотивацией трудоустройства молодых преподавателей в КемГУявляются интерес к педагогической и научной деятельности, стремление достичь определенного социального статуса. Большинство молодых преподавателей удовлетворены отношениями как с коллегами, так и со студентами, участвуют в корпоративных мероприятиях вуза или проявляют к этому интерес. Уровень своих профессиональных компетенций адаптанты считают либо высоким, либо средним. 
Основные проблемы, с которыми сталкиваются молодые преподаватели КемГУ, - это низкая заработная плата, соответственно, недостаточный уровень благосостояния; большой объем бумажной работы; отношение студентов к учебному процессу, низкая мотивация к учебе; большая эмоциональная и психическая нагрузка, загруженность другой работой, нехватка времени, недостаток собственного педагогического опыта; стиль работы администрации образовательного учреждения.

Обзорный анализ названных факторов приводит к выводу, что на социально-психологическом уровне адаптация молодых преподавателей КемГУ происходит более успешно, чем на профессионально-педагогическом и социально-экономическом. Эти наблюдения дают основание для более детального изучения этой проблемы с целью теоретического обоснования и развития управленческого механизма в создании благоприятных условий для успешной адаптации сотрудников.

Ключевые слова: профессиональная адаптация; факторы профессиональной адаптации; высшее образование; преподаватель вуза; Кемеровский государственный университет.

\section{BВЕАЕНИЕ}

П роблема адаптации представляет важную область исследований, расположенную на стыке различных областей знания. Вопросы профессиональной адаптации изучаются в социологии, педагогике, психологии, экономике, менеджменте. В менеджменте адаптация считается одним из важных направлений практики управления персоналом в современной организации и является, как пишет С. А. Сопоев, «с одной стороны, механизмом взаимодействия работника с организационным окружением, а с другой - одним из методов развития потенциала кадровых ресурсов организации» (Сопоев, 2013: 3). Несмотря на значительное количество научных исследований в этом направлении, многие вопросы, связанные с профессионально-педагогическим становлением преподавателя вуза, его адаптацией на новом месте, остаются открытыми, а возможности повышения эффективности этого процесса используются далеко не в полной мере. Как отмечает С. А. Сопоев, особая значимость адаптации молодых работников в нашей стране еще очень слабо осознается руководством и работниками служб персонала многих государственных и негосударственных предприятий, организаций и учреждений, где не применяются даже базовые программы адаптации не только для молодых специалистов, но и для других категорий работников (там же: 4).

Профессиональная адаптация молодого преподавателя вуза - это процесс взаимодействия личности и профессиональной среды, в ходе которого достигается оптимальное соответствие профессиональных способностей преподавателя требованиям, предъявляемым вузом. Профессиональная адаптация представляет собой двусторонний процесс между личностью и новой для нее социальной средой. Как подчеркивают Е. П. Бондарева, С. А. Сергеев, для взаимовыгодного (как для работодателя, так и для сотрудника) прохождения периода адаптации требуется развитие средств, методов и технологий адаптации как организационного процесса в целом (Бондарева, Сергеев, 2014: 28). Управление адаптивным процессом требует прежде всего изучения факторов, оказывающих положительное или негативное влияние на его эффективность. Факторы адаптации, как пишут А. А. Аширов и $\Lambda$. А. Резниченко, - это «условия, влияющие на течение, сроки, темпы и результат этого процесса» (Аширов, Резниченко, 2004: 110).

Актуальность представляемого исследования обусловлена, во-первых, имеющимися противоречиями, характерными для профессиональной деятельности молодых преподавателей. «В основе этих противоречий, - указывает А. А. Пережогина, - лежит несоответствие между комплексом требований, предъявляемых к профессио- 
нальной деятельности преподавателя высшей школы, и их реализацией в собственной профессиональной деятельности в конкретных условиях труда» (Пережогина, 2002: 34). Во-вторых, в сфере высшего образования по всей стране наблюдается старение профессорско-преподавательского состава; присутствует возрастающий спрос на молодых преподавателей. В связи с последним обстоятельством есть необходимость создания соответствующих условий для закрепления молодых кадров в высшей школе, интеграции их в университетскую среду и предоставления возможностей Аля постоянного роста, профессионального развития и повышения квалификации. И в-третьих, чаще всего в вузах отсутствуют программы адаптации молодых преподавателей, у кадровых служб нет комплексной информации об особенностях процесса адаптации молодых преподавателей, его условиях и факторах результативности. «Разрешение подобных противоречий, - пишет Е. Г. Черникова, - и является движущей силой процесса адаптации» (Черникова, 2010: 51).

На сегодняшний день Кемеровский государственный университет (КемГУ) является ведущим вузом Кемеровской области. По результатам 2014/2015 учебного года он вошел в сотню (96-е место) вузов Национального рейтинга университетов России (Сводный рейтинг ... : Электронный ресурс). Численность профессорско-преподавательского состава (ППС) в декабре 2014 г. составляла 608 чел. плюс 73 чел. - внешние совместители, 84 чел. - внутренние совместители из числа административно-управленческого, учебно-вспомогательного и профессорско-преподавательского состава. Из общего числа штатных преподавателей 475 женщин $(69,9 \%)$ и 133 мужчин $(30,1 \%)$; 102 доктора наук (16,8\%) и 361 кандидат (59,3\%). Штатных преподавателей в возрасте до 30 лет - 39 чел., что составляет всего 6,4\% от общего числа ППС.

Стоит отметить, что за последние четыре года количество преподавателей в вузе сократилось более чем на 100 чел. (на 15\%). Так, в 2011 г. в университете работали 712 чел. из числа ППС, в 2012 г. - 706, в 2013 г. - 691 и в 2014 г. - 608. По сравнению с 2011 г. в 2012 г. количество преподавателей сократилось на 0,8\%; в 2013 г. — на 2,1\% по отношению к 2012 г. В 2014 г. по отношению к 2013 г. сократилось на 12\%. Таким образом, можем говорить о том, что темпы уменьшения численности преподавателей возрастают с каждым годом.

С целью выявления факторов, влияющих на успешность профессиональной адаптации молодых преподавателей КемГУ, в 2015 г. нами было проведено анкетирование, в котором приняли участие 50 преподавателей вуза (как штатные сотрудники, так и совместители) в возрасте до 30 лет. Основную часть - 62\% - молодых преподавателей составляют женщины; мужчины - 38\%. Среди опрошенных $30 \%$ в возрасте 22-25 лет, 70\% - 26-30 лет. Большая часть преподавателей работают в должности ассистента - 58\%, должность старшего преподавателя занимают 26\%. Еще $16 \%$ - доценты и аспиранты.

Среди факторов трудовой адаптации традиционно выделяют две группы: субъективные и объективные. Объективные факторы - это факторы, связанные с трудовым процессом, они в наименьшей степени зависят от нового работника. Субъективные факторы определяются особенностями конкретного человека, его интересами и притязаниями.

\section{ОБЪЕКТИВНЫЕ ФАКТОРЫ}

Социальный фактор. Успешность адаптации молодого преподавателя вуза во многом зависит от того, какие возможности в содержании, особенностях и режиме деятельности предоставляет ему среда. Молодому преподавателю необходимо созда- 
ние благоприятных психологических контактов с руководством, коллегами и студентами. Успех социально-психологической адаптации как составляющей процесса профессиональной адаптации молодого преподавателя определяется его совместимостью с другими работниками - умением устанавливать контакты в ходе формального и неформального общения.

Аля оценки успешности респондентам было предложено ответить, насколько они удовлетворены этими взаимоотношениями. Исходя из того что большинство молодых преподавателей отметили, что отношения с коллегами их устраивают (62\% удовлетворены полностью, 30\% - скорее удовлетворены), сделано заключение о наличии позитивной адаптивной ситуации, стимулирующей и активизирующей прогрессивное развитие молодого преподавателя в КемГУ.

Большую роль в процессе адаптации молодых сотрудников играет корпоративная культура вуза. В частности, корпоративные мероприятия способствуют сплочению коллектива, дают возможность коллегам провести время в нерабочей обстановке, развивают коллективные традиции и обычаи. Опрос показал, что треть молодых преподавателей активно участвуют в большинстве мероприятий (34\%), им интересна неформальная сфера общения, они сами стремятся быстрее стать полноправными членами коллектива и чувствовать себя среди коллег комфортно. Одинаково распределились ответы между вариантами «участвую, но крайне редко» и «стараюсь, но не всегда есть на это время» - по $28 \%$. Оставшиеся $10 \%$ указали, что им это не интересно, либо затруднились ответить.

Высказываясь о своих взаимоотношениях со студентами, респонденты большей частью остановились на ответе «скорее удовлетворен» - 56\%, еще 40\% - «полностью удовлетворен». Таким образом, общую удовлетворенность отношениями со студентами отметили $96 \%$ респондентов. Молодые преподаватели в силу своего возраста могут, не затрудняясь, общаться со студентами на одном языке и лучше понимать, как выстраивать занятия, чтобы добиться наилучшего результата. В то же время 72\% опрашиваемых сказали о том, что недовольны отношением студентов к учебному процессу, и отметили их низкую мотивацию к учебе.

Стилем работы администрации образовательного учреждения оказались недовольны 30\% молодых преподавателей КемГУ.

Форма организачии труда. Этот фактор включает в себя различные аспекты организации труда: график и объем работы, техническое и учебно-методическое обеспечение, организация рабочего места и проч. Один из наиболее важных показателей в организации преподавательской деятельности у молодых сотрудников - «большой объем бумажной работы», на эту проблему указали $74 \%$ опрошенных. Постоянные изменения в требованиях к оформлению рабочих программ, методических пособий, планов и проч. занимают у всех преподавателей значительную часть времени. Молодым же преподавателям приходится эту «волокиту» осваивать впервые, а параллельно они работают над своими диссертационными исследованиями, посещают занятия в аспирантуре, а также впервые разрабатывают семинарские занятия и пишут лекции. При этом часто основная доля нагрузки достается молодым преподавателям в виде аудиторных часов, к тому же по совершенно разным дисциплинам.

Большинство преподавателей указали, что вполне удовлетворены материальнотехническим (58\%) и методическим (56\%) обеспечением учебного процесса. Неудовлетворительную оценку материальной оснащенности дали $30 \%$ респондентов, методическому сопровождению преподаваемой дисциплины - $28 \%$. 
Из числа положительных факторов преподавательской деятельности респонденты выделили «удобный график работы» - так ответили $34 \%$ опрошенных. В большей или меньшей степени преподаватели имеют возможность согласовывать расписание своих занятий. При этом в рабочем графике у них выделено время для самостоятельной и научной работы, поэтому им нет необходимости находиться на рабочем месте каждый день с утра до вечера. При этом $50 \%$ респондентов указали на нехватку времени.

Экономический фактор. Исследование показало, что среди социально-психологических и социально-экономических проблем, с которыми наиболее часто сталкиваются молодые преподаватели КемГУ, на первом месте стоит финансовый вопрос. Недовольство заработной платой отметила большая часть опрашиваемых $-84 \%$. Оплата труда научно-педагогических работников вузов имеет свою специфику, которая главным образом заключается в прямой зависимости размера заработной платы работника от его квалификации (ученой степени, ученого звания) и в определенной степени от стажа работы. Зарплаты молодых сотрудников вуза не высоки. При этом количество часов на ставку, как правило, обратно пропорционально занимаемой должности. Чем ниже должность, тем больше часов. Поэтому помимо работы в университете молодым преподавателям приходится решать свои материальные вопросы путем совмещения с другими видами заработка, что, естественно, не может не сказаться на качестве подготовки к занятиям, сроках написания диссертации, количестве научных публикаций и т. А. Именно поэтому работа в вузе для многих превращается в работу «для души», для тех, кто может себе это позволить. Преобладающее количество опрошенных по уровню материального благосостояния относят себя к среднеобеспеченным $-60 \%$ и малообеспеченным - $38 \%$.

\section{СУБЪЕКТИВНЫЕ ФАКТОРЫ}

Мотивированность труда. Одним из основных факторов профессиональной адаптации являются мотивы, обусловливающие устойчивость и продуктивность профессиональной деятельности человека. Адаптация молодых преподавателей должна в полной мере использовать мотивационный ресурс. Именно мотивация сотрудника при устройстве на работу влияет на его поведение и на процесс его адаптации в целом. Мотивы профессиональной деятельности считаются достаточно изученными и классифицированными. В качестве побудительных причин трудовой деятельности О. Н. Степанова выделяет мотивы общественного и материального характера, а также мотивы самоактуализации, самовыражения, самореализации, мотивы, связанные с удовлетворением потребности в общественном признании, в уважении со стороны других людей (Степанова, 2011: 170).

Наиболее привлекательной для молодых людей, решивших работать в КемГУ, является возможность заниматься научной и преподавательской деятельностью - эти варианты ответа выбрали $68 \%$ и $64 \%$ респондентов соответственно. Такое стремление вполне соответствует требованиям, предъявляемым к вузовскому преподавателю, который помимо педагогической деятельности должен заниматься наукой. K тому же именно продуктивная научная деятельность дает возможность наиболее успешного должностного роста и помогает молодым преподавателям оптимально завершить адаптационный период.

Второй по частоте упоминания ответ - стремление достичь определенного статуса $(60 \%)$. Человек, выбирающий работу преподавателя по этой причине, заинтересо- 
ван во мнении других людей относительно своей работы или профессии и стремится добиться признания в обществе путем выбора наиболее социально одобряемой работы или профессии. Ученые степени и звания, которые возможно получить в университетской среде, вполне способны реализовать этот мотив.

Молодых людей, принимающих решение работать преподавателем, в том числе привлекают творческий характер работы (38\%), возможность совмещать работу в вузе с другими видами деятельности (38\%) и желание остаться работать в знакомом со студенческих лет коллективе $(34 \%)$.

Уровень профессиональных компетениий. Процесс профессиональной адаптации предполагает освоение норм профессиональной деятельности, что обеспечивает качественную профессиональную деятельность, оптимальную работоспособность и является фундаментом для развития творческих способностей педагога, совершенствования профессионального мастерства, формирования индивидуального стиля деятельности. В качестве критериев самооценки профессиональных способностей молодых преподавателей были выбраны такие критерии, как общая эрудиция, знание преподаваемых дисциплин, умение передать знания студентам, умение эффективно использовать разнообразные формы контроля студентов и умение учитывать реакцию студентов. Респондентам было предложено оценить свои профессиональные знания, умения, навыки по трехбалльной шкале - высокий уровень, средний и низкий.

Высоким уровень своей общей эрудиции считают $48 \%$ опрошенных, ровно столько же оценили его как средний. Уровень знаний преподаваемых дисциплин большая часть (52\%) считают высоким, 48\% - средним. Наличие высокой способности передавать знания студентам отметили у себя 40\% респондентов, 58\% считают эту способность средней. Большая часть молодых преподавателей оценили свое умение эффективно использовать разнообразные формы контроля знаний студентов средним уровнем. Так ответили 66\% опрошенных. 30\% это профессиональное умение оценили высоко. Максимально әффективно учитывать реакцию студентов в педагогическом процессе могут половина респондентов - 50\%. На среднем уровне обладают этим умением $42 \%$.

Исследование показало, что молодые преподаватели КемГУ достаточно высоко оценивают наличие у себя профессионально значимых знаний, умений, навыков. Общий уровень профессиональной подготовки согласно балльной шкале составил 3,85 балла. При этом 40\% отметили отсутствие у себя необходимого для работы педагогического опыта. Сказывается отсутствие теоретической базы преподавания в высшей школе, разрыв между знаниями, полученными в ходе обучения в вузе, и знаниями, необходимыми для ведения определенных дисциплин. Не на всех факультетах в курсе основной программы обучения есть дисциплина «Педагогика». Ааже те студенты, которые ее изучали, практику проходили в средних образовательных учреждениях, где методика преподавания все же отличается от работы в высшем учебном заведении.

Психологический фактор. Общепризнанный факт, что сфера общения с людьми одна из самых сложных и эмоционально затратных. Преподавателям приходится выстраивать отношения с коллегами, руководством, административными службами, студентами - все это требует значительных усилий и высокого уровня стрессоустойчивости. Большую эмоциональную и психическую нагрузку в работе преподавателем вуза отметили $32 \%$ опрошенных. 


\section{ЗАКАЮЧЕНИЕ}

Проведенное исследование позволило обозначить основные факторы, положительно или негативно влияющие на адаптацию молодых преподавателей КемГУ. К числу положительных факторов мы отнесли позитивные отношения с коллегами, студентами; удобный график и возможность совмещать работу в вузе с другими видами деятельности; достаточное методическое обеспечение учебного процесса; творческий характер работы, возможность саморазвития; занятие научной и преподавательской деятельностью; социальный статус преподавателя вуза; достаточный уровень знаний, умений и навыков молодого преподавателя. Отрицательными факторами выступают низкая заработная плата, недостаточный уровень материального благосостояния, неблагоприятные жилищные условия; большое количество бумажной работы; низкая мотивация студентов к учебе; недостаток педагогического опыта; необходимость совмещать работу в вузе с другими видами деятельности; нехватка времени; большая психологическая и эмоциональная нагрузка; отношения с администрацией вуза; недостаточное материальное и методическое обеспечение учебного процесса.

Анкетирование позволило выявить проблемные зоны, которые в настоящее время имеются в деятельности молодых преподавателей КемГУ, а также определить факторы, способствующие созданию благоприятных условий для вхождения в профессиональное русло. Анализ показал, что на социально-психологическом уровне адаптация молодых преподавателей КемГУ происходит более успешно, чем на профессионально-педагогическом и социально-экономическом.

Специалисты в области управления персоналом в современных организациях сходятся во мнении, что основное условие успешного осуществления адаптации - наличие организационного механизма управления ею. Успешность решения задачи закрепления в вузе молодых преподавателей определяется качеством работы по управлению человеческими ресурсами в университете и зависит от осознания руководством значимости этой деятельности, реализации принципов системности и комплексности в управлении этим видом ресурсов. Обзорный анализ обозначенных факторов дает предпосылки для дальнейшего, более детального изучения адаптации молодых преподавателей КемГУ, что позволит теоретически обосновать и применить на практике систему благоприятных условий для успешной адаптации сотрудников.

\section{СПИСОК АИТЕРАТУРЫ}

Аширов, А. А., Резниченко, А. А. (2004) Управление персоналом. М. : Московский международный институт эконометрики, информатики, финансов и права. 193 с.

Бондарева, Е. П., Сергеев, С. А. (2014) Управление адаптацией персонала в вузе (на примере Кемеровского государственного университета) // Социогуманитарный вестник. № 1 (13). C. 28-31.

Пережогина, А. А. (2002) Профессионально-педагогическая адаптация начинающего преподавателя вуза : дис. ... канд. пед. наук. М. 165 с.

Петровичев, В. М. (2012) Процесс профессиональной адаптации молодых специалистов как объект научного исследования // Известия Тульского гос. ун-та. Гуманитарные науки. № 1. C. $43-52$.

Сводный рейтинг выборки университетов России. 2014/2015 [Электронный ресурс] // Национальный рейтинг университетов. URL: http://www.univer-rating.ru/rating_common.asp (дата обращения: 14.09.2015).

Сопоев, С. А. (2013) Адаптация молодых специалистов в современных российских организациях : автореф. дис. ... канд. социол. наук. М. 27 с. 
Степанова, О. Н. (2011) Мотивационный компонент в структуре профессиональной адаптации сотрудников УИС // Вестн. Бурятского гос. ун-та. Вып. 5. Психология, социальная работа. С. $168-172$.

Черникова, Е. Г. (2010) Состояние и противоречия социально-профессиональной адаптации молодых педагогов: социологический анализ : монография. Челябинск : Изд-во Челябинского гос. пед. ун-та. 184 с.

Lата поступления: 29.09.2015 2.

\author{
FACTORS OF PROFESSIONAL ADAPTATION \\ OF EARLY CAREER UNIVERSITY FACULTY \\ E. P. BONDAREVA \\ (UNIVERSITY OF AGRI IBRAHIM CHECHEN, TURKEY; \\ PleKHANOV RUSSiAN University OF ECONOMICS, KEMEROVO BRANCH), \\ S. A. SERGEEV \\ (UNIVERSITY OF AGRI IBRAHIM CHECHEN, TURKEY)
}

The topicality of our study is due to its treatment of a number of contradictions typical for Russia's system of higher education in general and for Kemerovo State University (located in the city of Kemerovo, Russia). These contradictions include discrepancies between the general employment requirements for university faculty and the specific situation at a university, and between the ageing of faculty and the absence of an adaptation system for early career educators at institutions of higher education institutions.

The article presents the outcomes of an empirical study of professional adaptation of junior faculty members aged 22-30 and employed by Kemerovo State University (KemSU). Conducted in 2015, the study revealed the trend towards the general reduction of faculty at KemSU. Early career teaching staff accounted for only $6.4 \%$ of the total number of full-time faculty. Since there is no established system of professional adaptation, early career faculty have to adapt to university teaching in a spontaneous fashion.

An opinion poll helped outline the problem areas for early career faculty, as well as a number of factors which create more favorable conditions for professional adaptation.

The main motivation for early career faculty was found to be in their commitment to teaching and research and their striving to achieve a certain social status. Most junior teaching staff are satisfied with the relations they have with colleagues and students. They participate in corporate events of the university, or at least express interest in those. Respondents assessed their own level of professional competence as average or high.

The main problems faced by early career staff at Kemerovo State University are low wages (and consequently, low welfare), large amount of paperwork, low students' motivation and their dismissive attitude to studying, great emotional and mental load, lack of time and/or pedagogical experience, and the style of governance adopted by the university administration. .

A review of these factors leads us to a conclusion that the adaptation of early career faculty members at KemSU is much more successful on the social and physiological level than on the professional, pedagogical and socioeconomic ones. This calls for a more detailed examination of the problem in order to provide a theoretical foundation for setting up an administrative mechanism which will help create favorable conditions for successful adaptation of faculty members.

Keywords: professional adaptation; factors of professional adaptation; higher education; early career faculty; Kemerovo State University

\title{
REFERENCES
}

Ashirov, D. A. and Reznichenko, L. A. (2004) Upravlenie personalom [Personnel management]. Moscow, Moscow International Institute of Econometrics, Informatics, Finance and Law Publ. 193 p. (In Russ.). 
Bondareva, E. P. and Sergeev, S. A. (2014) Upravlenie adaptatsiei personala v vuze (na primere Kemerovskogo gosudarstvennogo universiteta) [Managing personnel adaptation in higher school (the case of Kemerovo State University)]. Sotsio-gumanitarnyi vestnik, no. 1 (13), pp. 28-31. (In Russ.).

Perezhogina, A. A. (2002) Professional' no-pedagogicheskaia adaptatsiia nachinaiushchego prepodavatelia vuza [Professional pedagogical adaptation of early career university faculty] : Thesis... Candidate of Pedagogy. Moscow. 165 p. (In Russ.).

Petrovichev, V. M. (2012) Protsess professional'noi adaptatsii molodykh spetsialistov kak objekt nauchnogo issledovaniia [The process of professional adaptation of early career professionals as an object of research]. Izvestiia Tul' skogo gosudarstvennogo universiteta. Gumanitarnye nauki, no. 1, pp. 43-52. (In Russ.).

Svodnyi reiting vyborki universitetov Rossii 2014/2015 g [Composite sample rating of Russian universities]. Natsionalnyi reiting universitetov [National rating of universities] [online] Available at: http://www.univer-rating.ru/rating_common.asp (access date: 14.09.2015). (In Russ.).

Sopoev, S. A. (2013) Adaptatsiia spetsialistov v sovremennykb rossiiskikb organizatsiiakb [Employee adaptation in contemporary Russian organizations]. Thesis... Candidate of Sociology. Moscow. 27 p. (In Russ.).

Stepanova, O. N. (2011) Motivatsionnyi komponent v strukture professional'noi adaptatsii sotrudnikov UIS [Motivational component in the structure of professional adaptation of prison staff]. Vestnik Buriatskogo gosudarstvennogo universiteta, no. 5, pp. 168-172. (In Russ.).

Chernikova, E. G. (2010) Sostoianie $i$ protivorechiia sotsialno-professional'noi adaptatsii molodykb pedagogov: sotsiologicheskii analiz: monografiia [The current state and contradictions in social and professional adaptation of early career teachers: a sociological study]. Cheliabinsk. Cheliabinsk State Pedagogic University Publ. 184 p. (In Russ.).

Submission date: 29.09.2015.

Бондарева Евгения Петровна - кандидат филологических наук, доцент, доцент кафедры иностранных языков Кемеровского института (филиала) Российского экономического университета им. Г. В. Плеханова; доцент кафедры русского языка и литературы Университета им. Ибрагима Чечена в г. Агры, Турция. Адрес: 650992, Россия, г. Кемерово, пр. Кузнецкий, д. 39 , каф. 2408. Тел.: +7 (3842) 75-74-16. Эл. алрес: bondarevaep@list.ru

Сергеев Сергей Александрович - кандидат филологических наук, младший доцент кафедры русского языка и литературы Университета им. Ибрагима Чечена в г. Агры, Турция. Адрес: 04100, Турция, г. Агры, Университет им. Ибрагима Чечена. Тел.: +905452156534. Эл. адрес: SergeevSA@mail.ru

Bondareva Evgenia Petrovna, Candidate of Philology, Associate Professor, Department of Foreign Languages, Kemerovo Branch, Plekhanov Russian University of Economics; Associate Professor, Department of Russian Languages and Literature, University of Agri Ibrahim Chechen, Turkey. Postal address: 39 Kuznetskii Prospect, Kemerovo, Russian Federation, 650092. Tel.: +7 (3842)75-74-16. E-mail: bondarevaep@list.ru

Sergeev Sergey Aleksandrovich, Candidate of Philology, Assistant Professor of Department of Russian Languages and Literature, University of Agri Ibrahim Chechen, Turkey. Postal address: University of Agri Ibrahim Chechen, Turkey 04100. Tel.: +905452156534. E-mail: SergeevSA@mail.ru 